\title{
Reduced oxidative and nitrosative damage in murine experimental colitis in the absence of inducible nitric oxide synthase
}

\author{
B Zingarelli, C Szabó, A L Salzman
}

\begin{abstract}
Background-Oxidative and nitrosative stress have been implicated in the pathogenesis of inflammatory bowel diseases. Aims-To study the role of nitric oxide (NO) derived from inducible NO synthase (iNOS) in an experimental model of murine enterocolitis.

Methods-Trinitrobenzene sulphonic acid (TNBS) was instilled per rectum to induce a lethal colitis in iNOS deficient mice and in wild type controls. The distal colon was evaluated for histological evidence of inflammation, iNOS expression and activity, tyrosine nitration and malondialdehyde formation (as indexes of nitrosative and oxidative stress), myeloperoxidase activity (as index of neutrophil infiltration), and tissue localisation of intercellular adhesion molecule 1 (ICAM-1).

Results-TNBS administration induced a high mortality and weight loss associated with a severe colonic mucosal erosion and ulceration, increased myeloperoxidase activity, increased concentrations of malondialdehyde, and an intense staining for nitrotyrosine and ICAM-1 in wild type mice. Genetic ablation of iNOS gene conferred to mice a significant resistance to TNBS induced lethality and colonic damage, and notably reduced nitrotyrosine formation and concentrations of malondialdehyde; it did not, however, affect neutrophil infiltration and intestinal ICAM-1 expression in the injured tissue.

Conclusion-Data show that activation of iNOS is required for nitrosative and oxidative damage in experimental colitis. (Gut 1999;45:199-209)
\end{abstract}

Keywords: nitric oxide; nitric oxide synthase; inflammatory bowel disease; intercellular adhesion molecule 1; malondialdehyde; nitrotyrosine

Children's Hospital Medical Centre, Division of Critical Care, 3333 Burnet Avenue, Cincinnati, Ohio 45229, USA

B Zingarelli

C Szabó

A L Salzman

Correspondence to: Dr Zingarelli.

Accepted for publication 2 February 1999 inducible NO synthase (iNOS) has been proposed to be responsible for tissue injury in various experimental models, ${ }^{5-13}$ and ulcerative colitis in humans, where iNOS activity and raised concentrations of luminal nitrite have been detected in rectal dialysates and in biopsy specimens. ${ }^{14-17}$ However, the critical contribution of iNOS to the pathogenesis of inflammatory bowel disease (IBD) has not been clearly delineated.

It has been recently proposed that the cytotoxic effects of NO are mediated in part by peroxynitrite, a potent oxidant produced by the reaction of $\mathrm{NO}$ and superoxide anion. ${ }^{18}$ As a highly toxic reactive species, peroxynitrite indiscriminately attacks biomolecules critical to function and viability of the cell. ${ }^{19}$ During IBD the simultaneous production of superoxide and NO is likely to produce peroxynitrite and to promote oxidative reactions. Biochemical evidence for the formation of peroxynitrite has been provided in trinitrobenzene sulphonic acid induced ileitis in guinea pigs by immunohistochemical staining of nitrotyrosine, a marker of peroxynitrite induced protein modification, in epithelial cells. ${ }^{20}$ Furthermore, intracolonic administration of exogenous peroxynitrite produced severe mucosal damage in rats. ${ }^{21}$ In support of these findings, experimental studies have shown that the inflammatory response may be reduced by administration of NOS inhibitors. ${ }^{6-13}$ In contrast to these findings, however, it has been reported that genetic ablation of iNOS activation may exacerbate intestinal inflammation induced by intraluminal administration of acetic acid in mice. ${ }^{22}$ Other experimental studies have shown that only slight pharmacological inhibition of NO formation reduced colonic lesions, while a complete abolition of $\mathrm{NO}$ synthesis resulted in increased mucosal damage. ${ }^{23}$

To clarify further the biological role of activation of iNOS in intestinal inflammation, we induced colitis in mice lacking a functional gene for iNOS $\left(\mathrm{iNOS}^{-/}\right)$, while maintaining the capability to produce NO constitutively. ${ }^{24}$ Specifically, we evaluated the relation between colonic histological alterations, nitrosative and oxidative damage, and iNOS activation using an experimental model of IBD induced by intracolonic administration of TNBS in 50\% ethanol. ${ }^{25}$ We chose this model of IBD because

Abbreviations used in this paper: IBD, inflammatory bowel disease; ICAM-1, intercellular adhesion molecule 1; iNOS, inducible nitric oxide synthase; NO, nitric oxide; TNBS, trinitrobenzene sulphonic acid. 
it has macroscopic, histological, and biochemical alterations which are related to the production of free radicals, oxidants, and NO and are similar to the pathogenesis of colitis, in particular Crohn's disease. ${ }^{26} 27$

\section{Methods}

ANIMALS

Male and female iNOS ${ }^{-/-}$mice and iNOS ${ }^{+/+}$littermates $(129 / \mathrm{Sv} \times \mathrm{C} 57 \mathrm{BL} 10,20-22 \mathrm{~g})$ were from breeding pairs generated as previously described. ${ }^{24}$ The animals were a kind gift of Dr Laubach (Glaxo Wellcome Research Institute, Department of Molecular Biochemistry, Research Triangle Park, North Carolina). The experiments were carried out in accordance with National Institutes of Health guidelines and with the approval of the Institutional Review Board of the Children's Hospital Research Foundation, Cincinnati, Ohio.

INDUCTION OF EXPERIMENTAL COLITIS

Colitis was induced using the technique previously described. ${ }^{25}$ In fasted mice lightly anaesthetised with isoflurane, a $3.5 \mathrm{~F}$ catheter was inserted into the colon via the anus until approximately the splenic flexure $(4 \mathrm{~cm}$ from the anus). 2,4,6-Trinitrobenzene sulphonic acid (TNBS, $1 \mathrm{mg} / \mathrm{mouse}$ ) was dissolved in $50 \%$ ethanol (vol $/ \mathrm{vol})$ and injected $(0.1 \mathrm{ml})$ into the colon via the rubber cannula. Control animals received 50\% ethanol alone. Animals were then kept in a vertical position for $30 \mathrm{sec}-$ onds and returned to their cages. In the first experiment, animals were monitored for appearance of diarrhoea, loss of body weight, and survival for seven days. In a second set of experiments, groups of animals were sacrificed every 24 hours for seven days after TNBS administration; blood samples were collected by cardiac puncture, and a segment of the colon $4 \mathrm{~cm}$ long was excised for macroscopic damage evaluation. Tissue segments were then immediately frozen in liquid nitrogen and stored at $-70^{\circ} \mathrm{C}$ for the histological and immunohistochemical studies and for determination of myeloperoxidase activity and malondialdehyde concentrations.

\section{MEASUREMENT OF PLASMA NITRITE/NITRATE}

CONCENTRATION

Nitrite/nitrate production, an indicator of $\mathrm{NO}$ synthesis, was measured in plasma samples as previously described. ${ }^{28}$ Nitrate in the plasma was reduced to nitrite by incubation with nitrate reductase $(670 \mathrm{mU} / \mathrm{ml})$ and $\mathrm{NADPH}$ $(160 \mathrm{mM})$ at room temperature for three hours. After three hours, nitrite concentration in the samples was measured by the Griess reaction, by adding $100 \mu \mathrm{l}$ of Griess reagent $(0.1 \%$ naphthalethylenediamine dihydrochloride in $\mathrm{H}_{2} \mathrm{O}$ and $1 \%$ sulphanilamide in $5 \%$ concentrated $\mathrm{H}_{3} \mathrm{PO}_{4}$; vol 1/1) to $100 \mu \mathrm{l}$ samples. The optical density at $550 \mathrm{~nm}\left(\mathrm{OD}_{550}\right)$ was measured using a Spectramax 250 microplate reader (Molecular Devices Sunnyvale, California). Nitrate concentrations were calculated by comparison with $\mathrm{OD}_{550}$ of standard solutions of sodium nitrate prepared in saline solution.
EVALUATION OF COLONIC DAMAGE

After removal, the colon was gently rinsed with saline solution, opened by a longitudinal incision, and immediately examined under a microscope. The visible colonic damage was assessed by a semiquantitative scoring system adapted to the murine model. ${ }^{27}{ }^{29}$ The following morphological criteria were taken into consideration: score 0, no damage; score 1, localised hyperaemia without ulcers; score 2, linear ulcers, with no significant inflammation; score 3, linear ulcers with inflammation at one site; score 4, two or more major sites of ulceration and/or inflammation; score 5, two or more sites of inflammation and ulceration extending more than $1 \mathrm{~cm}$ along the length of the colon; score $6-8$, one point is added for each $\mathrm{cm}$ of ulceration beyond an initial $2 \mathrm{~cm}$. All measurements of damage were performed by two observers blinded to the experimental protocol.

HISTOPATHOLOGICAL ANALYSIS

For microscopic histological evaluation, formalin fixed tissues were embedded in paraffin; 5 $\mu \mathrm{m}$ sections were stained with haematoxylin and eosin and evaluated by light microscopy by a pathologist unaware of the experimental protocol.

IMMUNOHISTOCHEMISTRY FOR INOS

Frozen sections $(5 \mu \mathrm{m})$ were treated with $0.3 \%$ hydrogen peroxide for 15 minutes to block endogenous peroxidase activity and then rinsed briefly in phosphate buffered saline (PBS). Non-specific binding was blocked by incubating the slides with a blocking solution (0.1 M PBS containing $0.1 \%$ Triton X-100 and $2 \%$ normal goat serum) for two hours. To detect iNOS, rabbit polyclonal anti-iNOS antibody was applied in a dilution of $1 / 2000$ at $4^{\circ} \mathrm{C}$ overnight. Control sections included buffer alone or non-specific purified rabbit IgG. Immunoreactivity was detected with a biotinylated goat antirabbit secondary antibody and the avidin-biotin-peroxidase complex (Vectastain Elite ABC kit, Vector Laboratories). Colour was developed using diaminobenzidine. $^{20}$

IMMUNOHISTOCHEMISTRY FOR NITROTYROSINE Tyrosine nitration, a marker of nitrosative damage, was measured in colonic sections by immunohistochemistry. ${ }^{20}$ Frozen sections (5 $\mu \mathrm{m}$ thick) were fixed in $4 \%$ paraformaldehyde and incubated for two hours with a blocking solution $(0.1 \mathrm{M}$ PBS containing $0.1 \%$ Triton $\mathrm{X}-100$ and $2 \%$ normal goat serum) in order to minimise non-specific adsorption. Sections were then incubated overnight with $1 / 1000$ dilution of primary antinitrotyrosine antibody or with control solutions. Controls included buffer alone or non-specific purified rabbit IgG. Specific labelling was detected by incubating for 30 minutes with a biotin conjugated goat antirabbit IgG and amplified with avidinbiotin peroxidase complex (Vectastain Elite $\mathrm{ABC}$ kit, Vector Laboratories) after quenching endogenous peroxidase with $0.3 \% \mathrm{H}_{2} \mathrm{O}_{2}$ in $100 \%$ methanol for 15 minutes. Diaminoben- 
zidine was used as a chromogen. To quantitate the degree of nitrotyrosine staining, a $0-4$ grading system was used: 0 , no staining; 1-3, increasing degrees of intermediate staining; 4, extensive staining. In each experimental group, five or six sections were evaluated by two independent observers blinded to the experimental protocol.

ASSAY OF MYELOPEROXIDASE ACTIVITY

Myeloperoxidase activity was determined as the index of neutrophil accumulation. ${ }^{30} \mathrm{Co}-$ lonic tissues were homogenised in a solution containing $\quad 0.5 \% \quad$ hexadecyltrimethylammonium bromide dissolved in $10 \mathrm{mM}$ potassium phosphate buffer $(\mathrm{pH} 7)$ and centrifuged for 30 minutes at $20000 \mathrm{~g}$ at $4^{\circ} \mathrm{C}$. An aliquot of the supernatant was then allowed to react with a solution of tetramethylbenzidine (1.6 $\mathrm{mM}$ ) and $0.1 \mathrm{mM} \mathrm{H}_{2} \mathrm{O}_{2}$. The rate of change in absorbance was measured by spectrophotometry at $650 \mathrm{~nm}$. Myeloperoxidase activity was defined as the quantity of enzyme degrading $1 \mu \mathrm{mol} / \mathrm{min}$ of peroxide at $37^{\circ} \mathrm{C}$ and was expressed in milliunits per $100 \mathrm{mg}$ weight of tissue.

IMMUNOHISTOCHEMISTRY FOR ICAM-1

ICAM-1 expression was evaluated in colon sections by immunohistochemistry. ${ }^{31}$ Frozen sections ( $5 \mu \mathrm{m}$ thick) were fixed in $4 \%$ paraformaldehyde and incubated in $2 \%$ hamster serum for two hours in order to minimise nonspecific adsorption. Sections were then incubated overnight at $4^{\circ} \mathrm{C}$ with monoclonal biotinylated antibodies directed at ICAM-1 (hamster antimouse CD54) at a dilution of 1/500. Controls included buffer alone or non-specific purified IgG. Antibody binding sites were visualised with an avidin-biotin peroxidase complex immunoperoxidase technique (Vector Laboratories) after quenching endogenous peroxidase with $0.3 \% \mathrm{H}_{2} \mathrm{O}_{2}$ in $100 \%$ methanol for 15 minutes. Diaminobenzidine was used as a chromogen. To quantitate the degree of ICAM-1 staining, a 0-4 grading system was used: 0 , no staining; 1 , constitutive presence of staining along endothelial wall; 2, increased staining along the endothelial wall; 3 , increased staining along the endothelial wall, and presence of staining on infiltrated inflammatory cells; 4, increased staining along the endothelial wall, and presence of staining on infiltrated inflammatory cells and epithelial cells.

MEASUREMENT OF COLONIC MALONDIALDEHYDE Tissue concentrations of malondialdehyde were determined as an index of lipid peroxidation. ${ }^{32}$ Tissue samples were homogenised in $1.15 \% \mathrm{KCl}$ solution. An aliquot (100 $\mu \mathrm{l})$ of the homogenate was added to a reaction mixture containing $200 \mu \mathrm{l}$ of $8.1 \%$ sodium dodecyl sulphate (SDS), $1500 \mu 1$ of $20 \%$ acetic acid ( $\mathrm{pH} 3.5), 1500 \mu \mathrm{l}$ of $0.8 \%$ thiobarbituric acid, and $700 \mu$ distilled water. Samples were then boiled for one hour at $95^{\circ} \mathrm{C}$ and centrifuged at $3000 \mathrm{~g}$ for 10 minutes. The absorbance of the supernatant was measured by spectrophotometry at $532 \mathrm{~nm}$ and com- pared with a standard curve obtained with 1,1,3,3-tetramethoxypropane. Data were expressed as $\mu \mathrm{M}$ per $100 \mathrm{mg}$ weight of tissue.

MATERIALS

Primary iNOS and antinitrotyrosine antibodies were purchased from Upstate Biotech (Saranac Lake, New York). Primary monoclonal ICAM-1 (CD-54) antibody was purchased from Pharmingen (San Diego, California). Hamster serum was purchased from Jackson ImmunoResearch Laboratories (West Grove, Pennsylvania). Reagents, secondary, and nonspecific IgG antibodies for immunohistochemical analysis were from Vector Laboratories Inc. (Burlingame, California). All other chemicals were from Sigma/Aldrich (St Louis, Missouri).

STATISTICAL ANALYSIS

All data are expressed as mean (SEM); $n$ refers to the number of mice. Statistical differences between groups were calculated by one and two way analysis of variance (ANOVA) followed by a Bonferroni post hoc test. Survival differences were analysed with the $\chi^{2}$ test. Results were considered significant at a $\mathrm{p}$ value of less than 0.05 .

\section{Results}

SEVERITY OF TNBS INDUCED COLITIS IS REDUCED IN iNOS ${ }^{-/-}$MICE

Intracolonic administration of TNBS in wild type mice induced a severe illness characterised by bloody diarrhoea and a dramatic loss of body weight and resulted in a high mortality rate (only two mice out of 20 survived seven days after TNBS treatment). In contrast, iNOS $^{-/-}$mice seemed notably less sensitive to the inflammatory effects of TNBS: animals experienced a mild diarrhoea and a less pronounced loss of body weight, and only six animals out of 16 died during the experimental observation period (fig 1A, B).

TNBS INDUCED COLONIC DAMAGE IS ATTENUATED IN iNOS $^{-/}$MICE

Macroscopic evaluation of the distal colon and rectum up to 72 hours after TNBS treatment revealed the presence of mucosal oedema and haemorrhagic ulcerations in both wild type and iNOS $^{-/-}$mice. In wild type mice mucosal damage was still severe up to six and seven days after TNBS administration. However, at four days after colitis induction, in iNOS deficient mice, the mucosal surface of the colon and rectum showed only localised erythema or no damage, indicative of a significant resolution of colitis in comparison to the wild type mice $(\mathrm{p}<0.05$; see fig $1 \mathrm{C}$ for damage score). Histological examination confirmed the above observations (fig 2). In colonic sections from $\mathrm{iNOS}^{+/+}$mice, haemorrhagic necrosis of the mucosa was associated with infiltration of inflammatory cells into the lamina propria and submucosa. Histopathological evaluation of the colon and rectum of TNBS treated $\mathrm{iNOS}^{-/}$ mice showed a remarkable reduction in mucosal damage with recovering process of the epithelium starting at four days after induction 

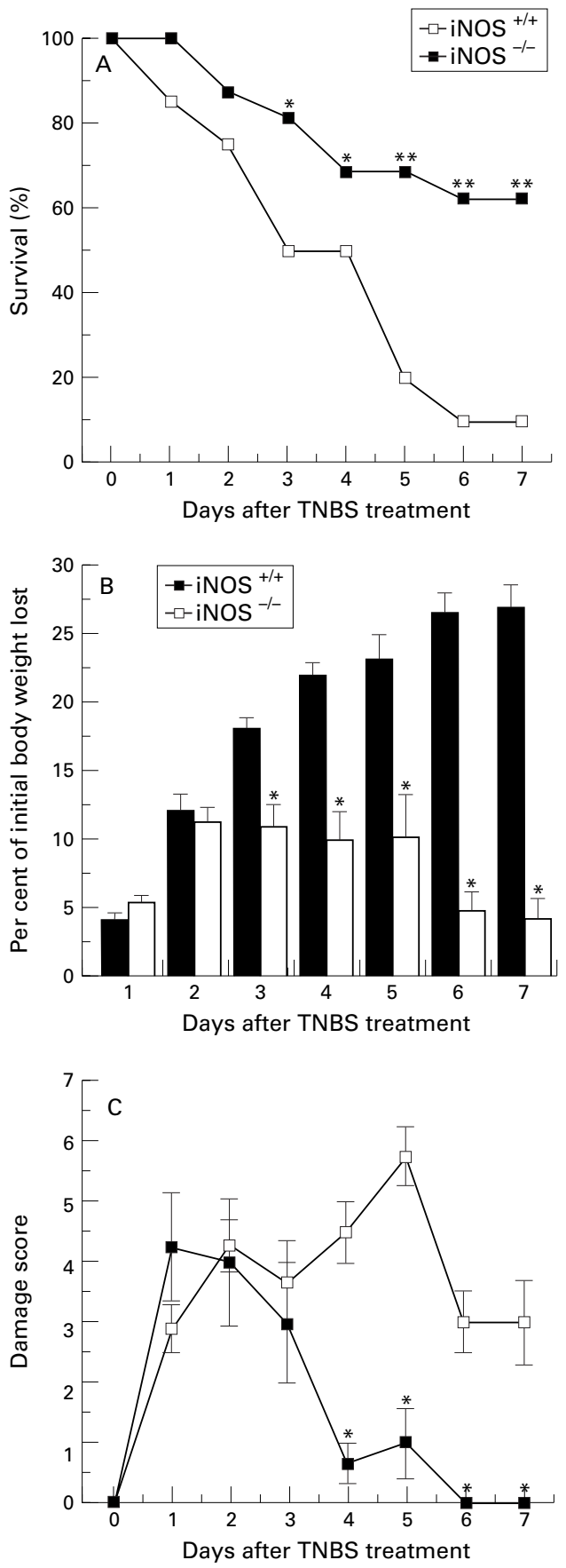

Figure 1 Survival (A), weight loss (B), and damage score $(C)$ in iNOS $^{+/+}$and $i \mathrm{NOS}^{-1-}$ mice after TNBS intracolonic administration. Each data point is the mean (SEM) of 8-20 animals for each group. ${ }^{\star} p<0.05$, ${ }^{\star *} p<0.01$.

of colitis. However, a massive infiltration of inflammatory cells was still present in the lamina propria and submucosa of colonic sections of TNBS treated iNOS ${ }^{-/-}$mice (fig 2).

TNBS ADMINISTRATION INDUCES INOS EXPRESSION IN WILD TYPE MICE

Induction of colitis in TNBS treated wild type mice was associated with expression of iNOS, which was localised mainly at the apical part of the epithelial cells, as determined by immunohistochemistry. Expression of iNOS was associated with a remarkable increase in plasma nitrite/nitrate concentration. In the iNOS knockout animals, low nitrite/nitrate concentrations were detected with no detectable iNOS expression (fig 3).

COLONIC INFILTRATION OF NEUTROPHILS AND ICAM-1 EXPRESSION WAS NOT AFFECTED IN iNOS $^{-/-}$MICE AFTER TNBS ADMINISTRATION As abrogation of colonic damage was not paralleled by a reduction in inflammatory cells, we next sought to estimate better the infiltration of neutrophils by quantification of tissue activity of myeloperoxidase, a specific enzyme of azurophilic granules and directly correlated to the number of neutrophils. In parallel with increased infiltration of inflammatory cells observed in the histological specimens, myeloperoxidase activity was significantly increased in TNBS treated iNOS ${ }^{+/+}$mice after TNBS treatment. Similar high concentrations of myeloperoxidase activity were found in TNBS treated NNOS $^{-/-}$mice (fig 4A).

We also evaluated the intestinal expression of ICAM-1. In colonic tissue from $\mathrm{iNOS}^{+/+}$or iNOS $^{-/-}$control mice at day 0 , immunostaining for ICAM-1 was present along the endothelium of small vessels of the lamina propria and submucosa, consistent with a constitutive expression of ICAM-1 on endothelial cells (figs $4 \mathrm{~B}$ and 5). After TNBS administration, the staining intensity for ICAM-1 increased along the endothelium and was found also on epithelial cells and neutrophil surface with similar distribution and extent in both iNOS $^{+/+}$and $\mathrm{iNOS}^{-/-}$mice (figs $4 \mathrm{~B}$ and 5).

NITROSATIVE AND OXIDATIVE DAMAGE WAS REDUCED IN TNBS TREATED iNOS $^{-/}$MICE

It has been suggested that neutrophils contribute significantly to the mucosal damage of colitis by releasing radicals and oxidant molecules. ${ }^{33} 34$ In the present study, we found raised tissue concentrations of malondialdehyde, indicative of a notable lipid peroxidation (fig 6A). An intense immunostaining for nitrotyrosine was indicative of a nitrosative injury in TNBS treated iNOS ${ }^{+/+}$wild type mice (figs $6 \mathrm{~B}$ and 7). Surprisingly, genetic deficiency of iNOS in TNBS treated mice prevented the increased formation of malondialdehyde and nitrotyrosine staining, even in the presence of a massive neutrophil infiltration (figs $6 \mathrm{~B}$ and 7 ).

\section{Discussion}

Our data show that mice with a targeted deletion of the iNOS gene are significantly more resistant to death and pathological changes in the colon and rectum associated with TNBS induced colitis compared with wild type controls. Thus, these results suggest that the development and persistence of colonic injury require the presence of a functional iNOS gene and iNOS generated NO.

ACTIVITY OF INOS IS A CRUCIAL PREREQUISITE OF OXIDATIVE AND NITROSATIVE DAMAGE IN TNBS INDUCED COLITIS

It has been proposed that reactive oxygen and nitrogen species play a key role in IBD. These species are cytotoxic agents, inducing lipid 


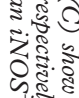

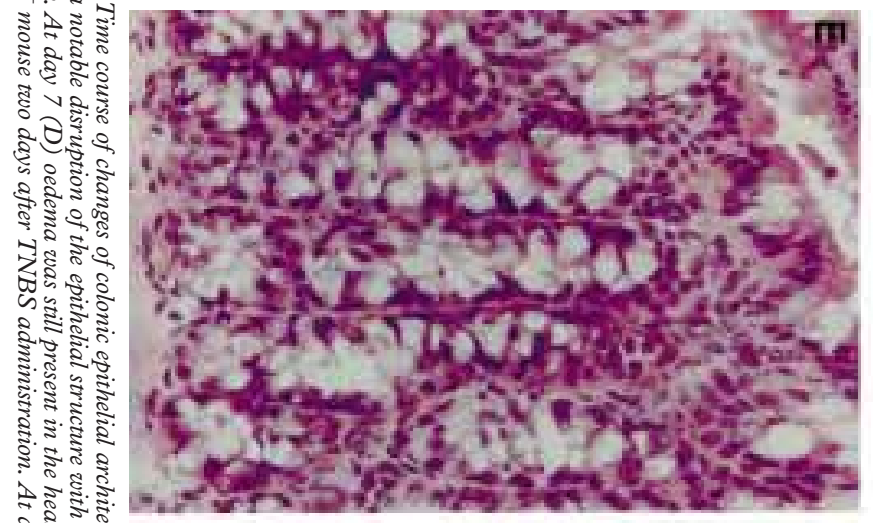

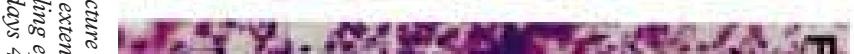

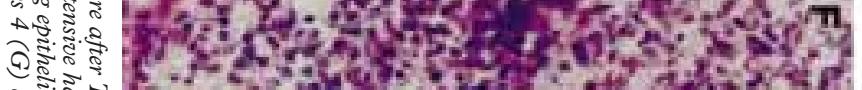

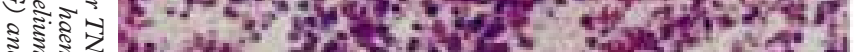
vo

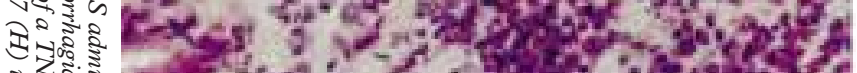

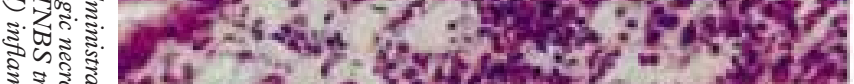

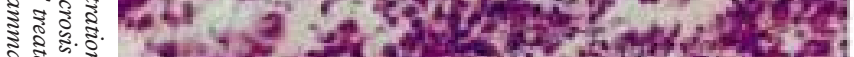

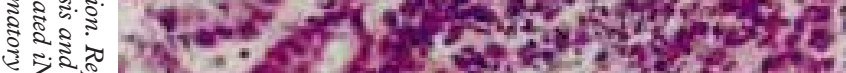

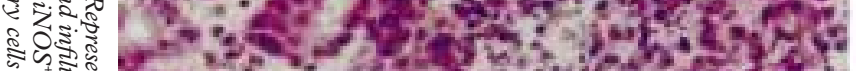

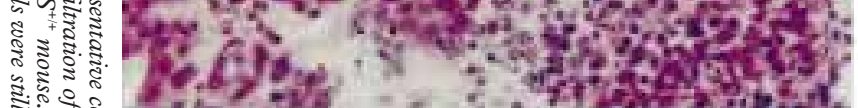

\section{ㄴำ}
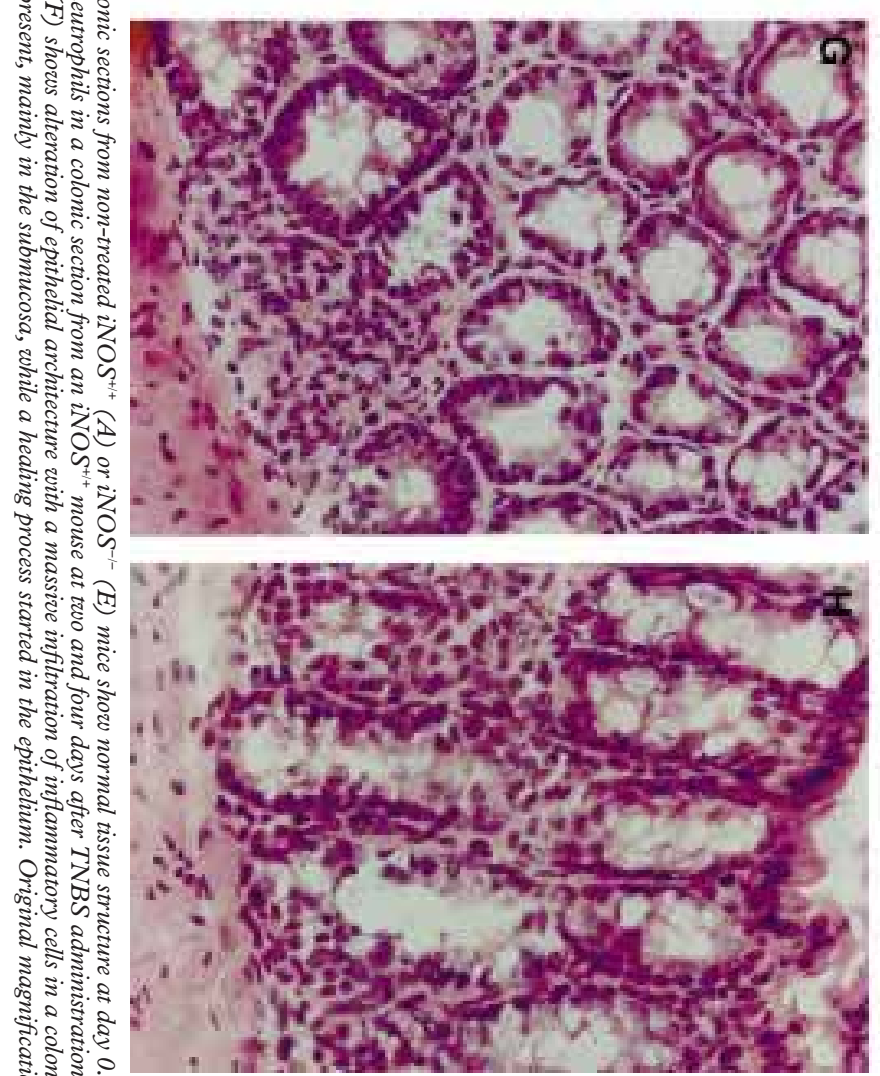

$\times$ 乐

현
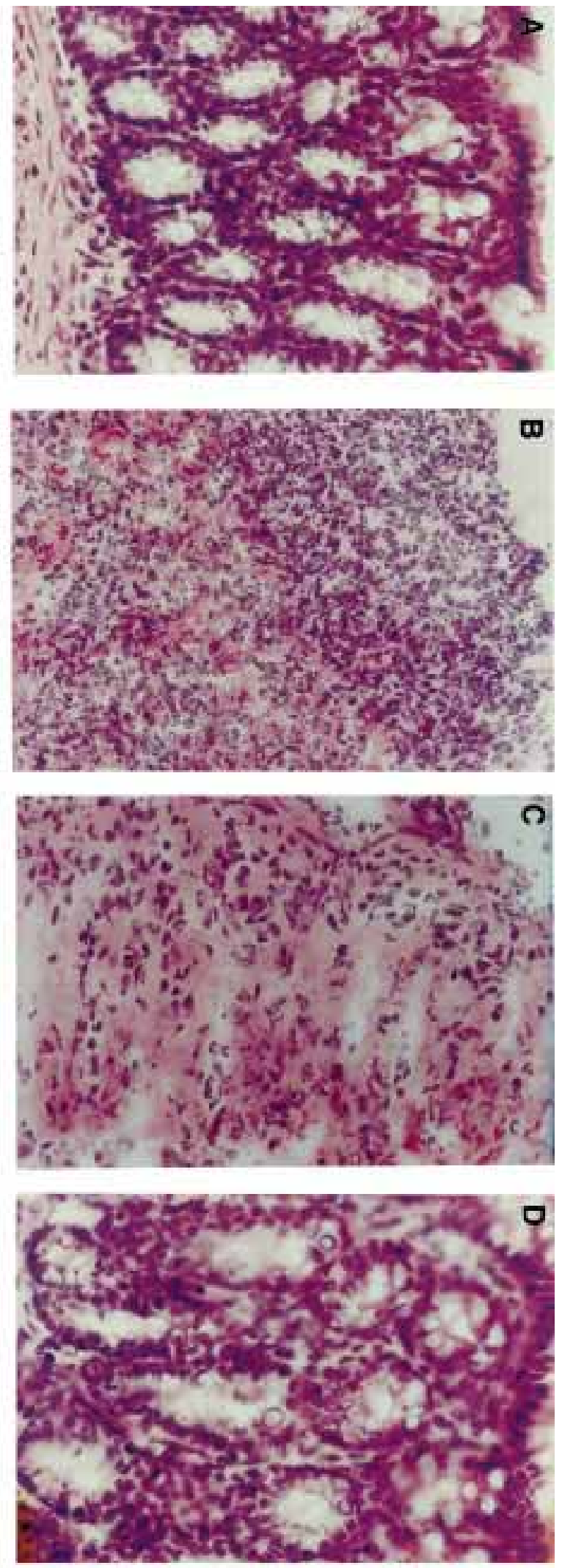

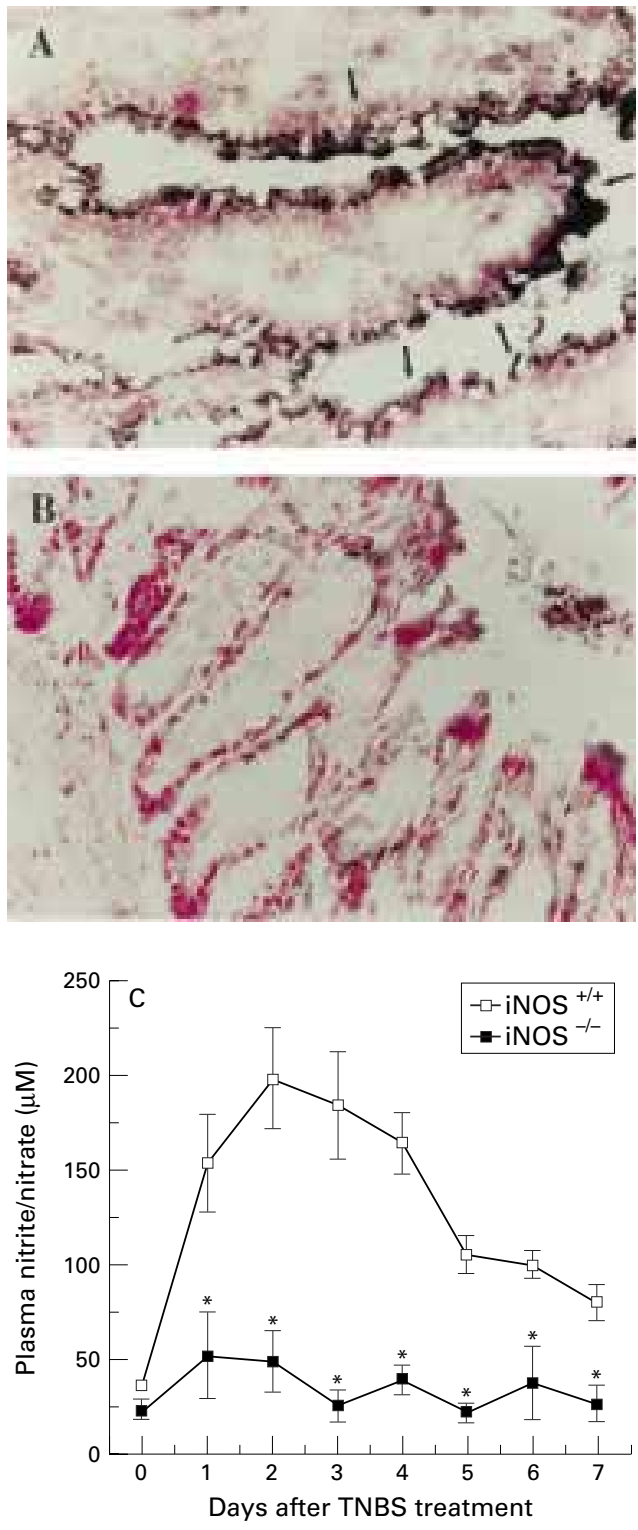

Figure 3 Immunohistochemical localisation of iNOS ( $A$ and $B$ ) and plasma nitrite/nitrate concentrations (C). (A) shows a diffuse dark staining localised in the apical epithelium (arrows) in the inflamed colon of an $i \mathrm{NOS}^{+/+}$ mouse four days after TNBS administration. (B) shows no staining in a colonic section of an iNOS ${ }^{-/-}$mouse four days after TNBS administration. Original magnification $\times 400$. (C) shows the time course of plasma nitrite/nitrate concentrations after TNBS administration. Each data point is the mean (SEM) of 4-8 animals for each group. ${ }^{*} p<0.05$.

peroxidation and other cellular oxidative stress by cross linking proteins, lipids, and nucleic acids, which then cause cellular dysfunction, damage, and eventually death. Evidence consistent with damage by reactive species is provided by the increase in lipid peroxides in rectal biopsy specimens from patients with ulcerative colitis. ${ }^{35-37}$ In our experiments we found that the mucosal damage induced by intracolonic administration of TNBS in wild type mice (that is, those with a normal iNOS gene), was associated with high concentrations of colonic thiobarbituric acid reactant malondialdehyde, which is considered a good indicator of lipid peroxidation. ${ }^{32}$
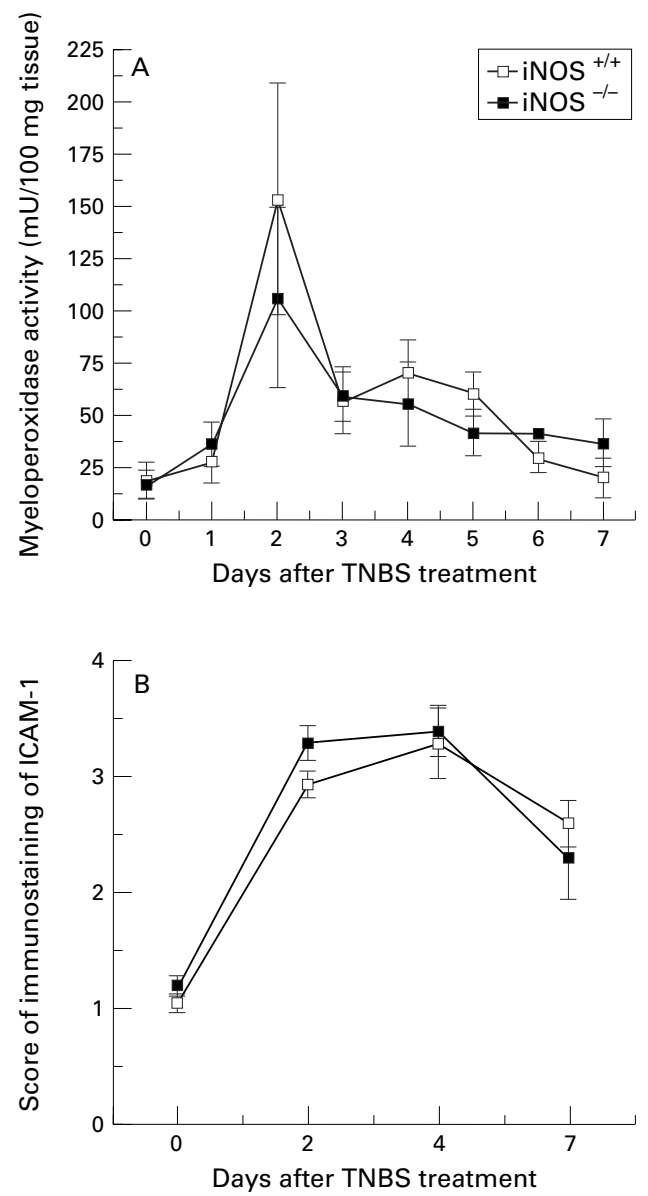

Figure 4 Time course of myeloperoxidase activity $(A)$ and score of immunostaining of ICAM-1 (B) in tissues from $i \mathrm{NOS}^{+/+}$and $i \mathrm{NOS}^{-/-}$mice after induction of colitis. Each data point is the mean (SEM) of eight animals for each group.

Recent evidence indicates also that nitration of tyrosine can result from a number of chemical reactions, and can be considered as a global marker of nitrosative stress. ${ }^{19} 38$ Nitrotyrosine can be formed from the reaction of nitrite with hypochlorous acid or the reaction of nitrite with myeloperoxidase and hydrogen peroxide. ${ }^{38-40}$ In our experiments, we found increased immunohistochemical expression of iNOS, mainly localised in the apical side of epithelial cells. This finding is supported by other reports showing that iNOS staining is always at the superficial part of the crypt and the surface of the mucosa, while no other positive cells or part other than apical were found in human colonic sections of ulcerative colitis. ${ }^{41}{ }^{42}$ Furthermore, we found a positive immunohistochemical staining for nitrotyrosine mostly on epithelial cells and in the area of infiltrated inflammatory cells, suggesting that peroxynitrite or other nitrogen derivatives and oxidants are formed in vivo and may contribute to tissue injury. These data are consistent with previous findings that immunohistochemical staining for nitrotyrosine was colocalised on epithelial cells with iNOS immunoreactivity in a TNBS model of guinea pig ileitis ${ }^{20}$ and in active Crohn's lesions in humans. ${ }^{43}$ The pathogenic role of nitrogen derived species such as peroxynitrite in IBD is further supported by the fact that intracolonic 


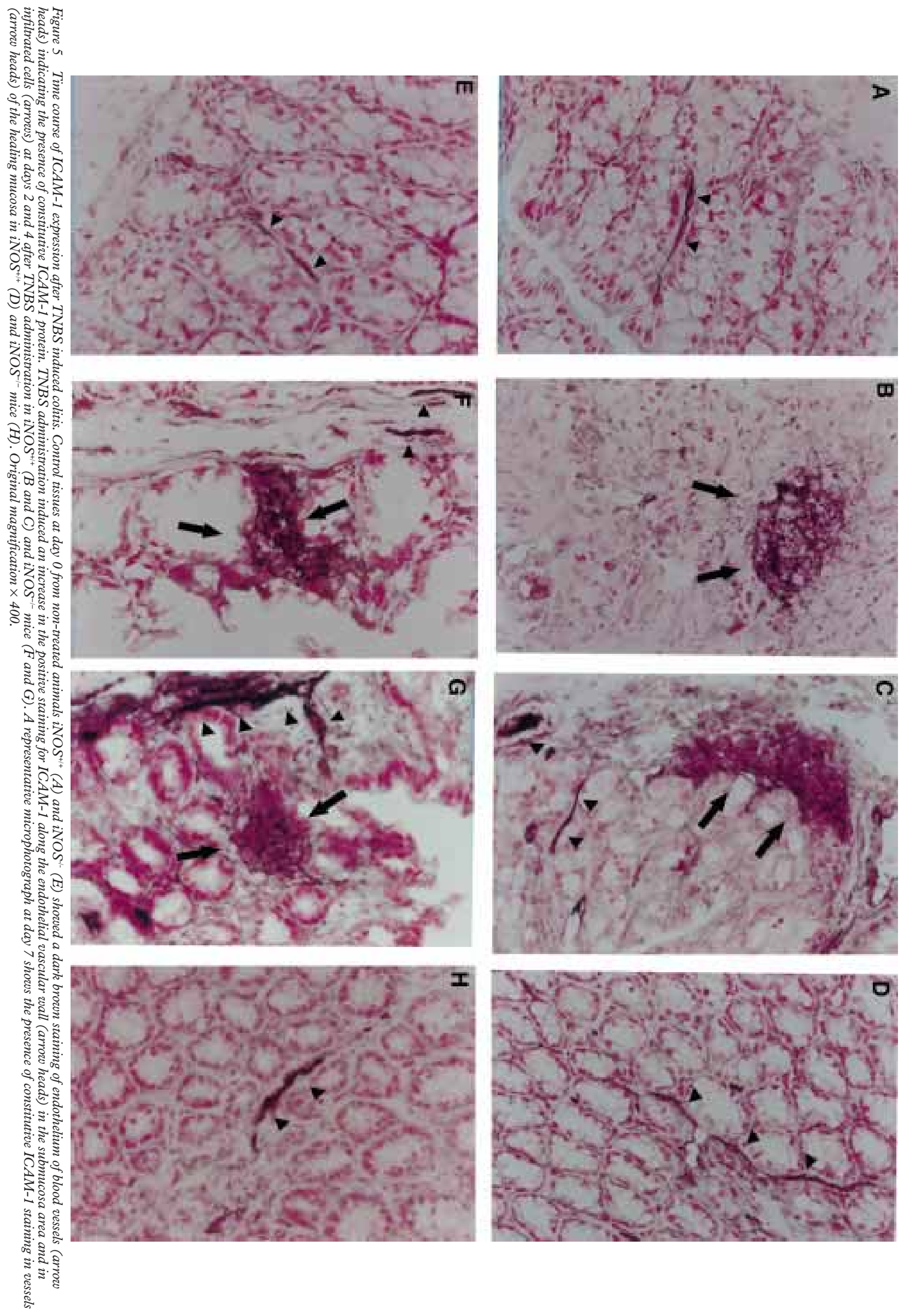

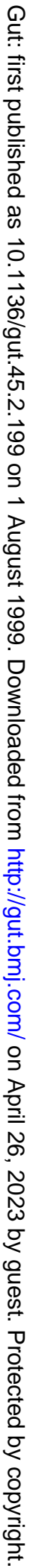



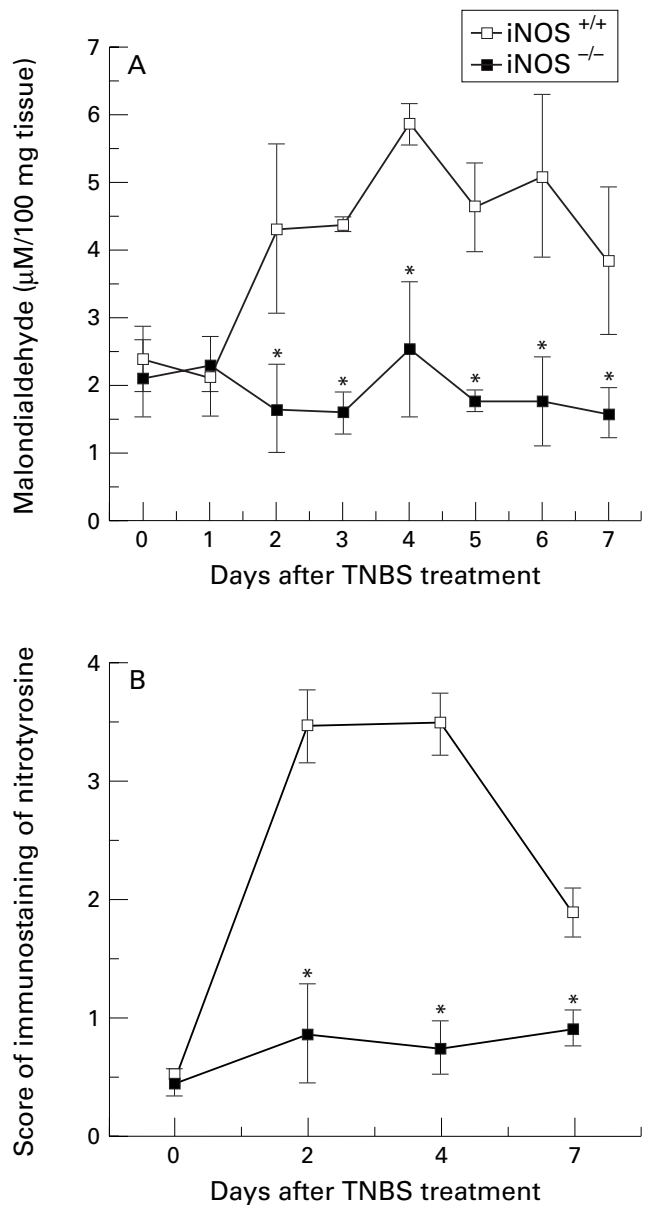

Figure 6 Time course of colonic concentrations of malondialdehyde $(A)$ and score of immunostaining of nitrotyrosine (B) in tissues from TNBS treated iNOS and $i \mathrm{NOS}^{-/-}$mice. Each data point is the mean (SEM) of eight animals for each group. ${ }^{\star} p<0.05$.

administration of exogenous peroxynitrite induces a severe colonic inflammation which mimics the features of both ulcerative colitis and Crohn's disease. ${ }^{21}$

We observed that epithelial disruption was similar in wild type and iNOS ${ }^{-/}$mice at the earlier time (up to 72 hours after TNBS instillation). However, iNOS deficiency prevented the formation of tissue malondialdehyde and nitrotyrosine staining in TNBS treated animals. Furthermore, iNOS ${ }^{-/-}$mice seemed more resistant to TNBS induced lethal disease with a significant resolution of the macroscopic and histological signs of the inflammatory process at the later time. Therefore, although the lack of iNOS activity does not prevent the nonspecific chemical induced colonic damage secondary to the caustic nature of TNBS, it prevents the persistence of damage due to the involvement of $\mathrm{NO}$ driven inflammatory pathways. Thus, these findings, coupled with the inhibitor effects on nitrotyrosine formation and lipid peroxidation, suggest that the protective effect of iNOS gene ablation is probably due to reduced production of toxic oxidants during the inflammatory process. It has been proposed, however, that peroxynitrite formation may also be produced from the reaction of superoxide anion with constitutive NOS derived NO. ${ }^{44}$ Our study, showing a notable reduction in malondialdehyde and nitrotyrosine in NNOS $^{-/}$mice, which still maintain the capability to produce NO from the constitutive enzyme, ${ }^{24}$ suggests that an overproduction of $\mathrm{NO}$ and peroxynitrite and/or other nitrogen derivatives from iNOS plays the major role in the oxidative and nitrosative stress of IBD.

THE BENEFICIAL EFFECTS OF GENETIC ABLATION OF INOS IN TNBS INDUCED COLITIS ARE NOT RELATED TO AN ALTERATION IN NEUTROPHIL RECRUITMENT

Neutrophils have been considered to play a crucial role in the development and full manifestation of gastrointestinal inflammation, as they represent a major source of free radicals in the inflamed colonic mucosa. ${ }^{33-35}$ Neutrophil infiltration seems to be mediated, at least in part, by an increase in the expression of ICAM-1 on endothelial cells, neutrophils, and epithelial cells. ${ }^{45-49}$ In this regard, NO functions as an inhibitor of the neutrophil-endothelial cell interaction, most probably by inhibiting expression of adhesion molecules on the endothelial surface. ${ }^{4}$ A major finding of this study was that, although the $\mathrm{iNOS}^{-/-}$mice showed a remarkable recovery of the mucosal morphology associated with a reduction in oxidative and nitrosative damage after TNBS administration, infiltration of polymorphonuclear neutrophils was similar in tissue extent and distribution to that seen in TNBS treated iNOS $^{+/+}$mice. Furthermore, ICAM-1 was expressed in endothelial and epithelial cells, and neutrophils in the distal colon in both TNBS treated wild type and $\mathrm{iNOS}^{-/-}$mice. Thus, in contrast with previous findings showing that genetically iNOS deficient mice have enhanced leucocyte-endothelium interactions in endotoxaemia, ${ }^{50}$ our data suggest that activation of inducible NOS does not contribute to the regulation of neutrophil infiltration. Notably, Khan et al reported that iNOS ${ }^{-/-}$mice subjected to Toxoplasma gondii infection showed a notable reduction in hepatocellular dysfunction and necrosis of the small intestine but had no difference in neutrophil infiltration, compared with parenteral controls. ${ }^{51}$

Substantial evidence supports the view that the maintenance of the constitutive production of NO is a critical homoeostatic regulator for maintaining microvascular patency, permeability, tissue perfusion, and mucosal barrier function, and for inhibiting neutrophil infiltration and activation. ${ }^{1-3}$ In this regard, it is noteworthy that in the gastrointestinal tract, acute nonselective blockade of constitutive and induced NO synthesis augments leucocyte adhesion to the microvascular endothelium ${ }^{3}$ and exacerbates the damage associated with ethanol insult $^{52}$ and intracolonic administration of TNBS. $^{23}$

ACTIVATION OF INOS AMPLIFIES THE OXIDANT DEPENDENT PATHWAY INJURY IN THE INFLAMED COLONIC MUCOSA

The findings presented here clearly illustrate that, in spite of a massive neutrophil infiltration, which is expected to maintain the production of oxygen derived free radicals, oxi- 

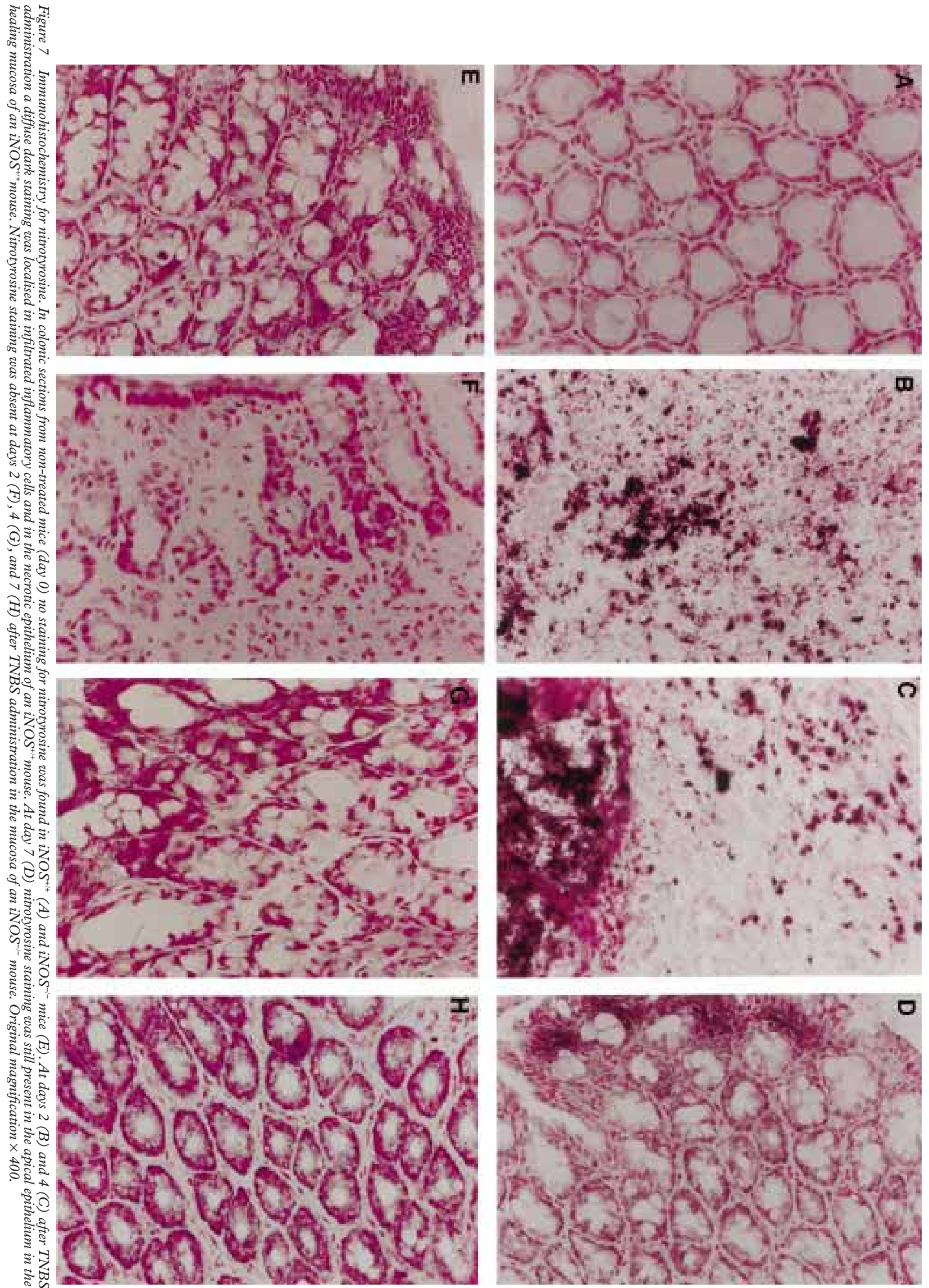

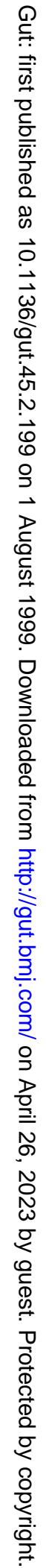


dative and nitrosative damage in IBD requires the presence of a functional iNOS gene. In accordance with our findings, previous studies have shown that infiltration of inflammatory cells was not essential for the development of the major pathological features of colitis induced by phorbol myristate acetate, acetic acid, or TNBS, ${ }^{53}$ and neutrophil depletion failed to attenuate colonic injury. ${ }^{53-55}$ Several hypotheses may explain this phenomenon. Although NO itself is a weak oxidant, biochemical studies have shown that NO rapidly interacts with superoxide anion to yield peroxynitrite and its conjugate acid, peroxynitrous acid, which then decomposes to form highly reactive oxidant species, such as hydroxyl and nitrogen dioxide. Both $\mathrm{NO}$ and peroxynitrite, directly or via reactive intermediates, may induce cytotoxicity via a number of mechanisms including tyrosine nitration, lipid peroxidation, DNA strand breaks, and the consequent activation of poly-ADP ribose synthase. ${ }^{192856-60}$ Furthermore, nitrogen centred oxidants may also degrade the ironsulphur clusters of mammalian mitochondrial $\mathrm{NADH}$-coenzyme $\mathrm{Q}$ reductase, succinate dehydrogenase, aconitase, and ATPase..$^{57}$ As a consequence, intracellular iron homoeostasis may be disrupted, providing a catalyst for further generation of deleterious oxygen species from neutrophils. ${ }^{62}$

\section{Conclusions}

Utilising a murine iNOS deficient model of chemically induced colitis, we have obtained strong evidence implicating iNOS as a critical element in the pathogenesis of inflammatory bowel injury. Our data are in general agreement with previous pharmacological studies of experimental colitis, in which NOS inhibition has had a favourable effect on mucosal injury. ${ }^{6-13}$ In contrast to these previous reports and our present study, McCafferty et al reported a deleterious effect of iNOS deficiency on the ability to resolve a colitic injury in an experimental model of inflammatory bowel disease induced by rectal instillation of acetic acid. $^{22}$ The discrepancy in these reports may relate to the difference in the stimuli used to induce the injury. Although the acetic acid and TNBS induced colitis models reproduce many of the characteristic features of human IBD, there are significant differences in the extension of intestinal damage, the time requirement to develop lesions, and the relative involvement of iNOS independent pathways. ${ }^{26}$ It is noteworthy that similar controversial roles have been ascribed to iNOS derived NO in a variety of pathophysiological conditions. While a number of studies have reported that genetic ablation of iNOS may exert beneficial effects in endotoxic shock, infection by Toxoplasma gondii, and autoimmune vasculitis, ${ }^{5163-65}$ other studies have reported that genetic ablation of iNOS may exacerbate the inflammatory process in endotoxaemia, encephalomyelitis, and tuberculosis. ${ }^{246667}$ Further experiments are needed in order to explain these differences, which have important implications for clinical therapeutic strategies based on inhibition.
Furthermore, TNBS induced colitis may not represent a suitable model for investigatation of the pathophysiology of human Crohn's disease or ulcerative colitis, which are spontaneous and heterogeneous disorders with multiple aetiological and pathogenic mechanisms. Nevertheless, the TNBS induced colitis model reproduces many of the characteristic features of human IBD, including generation of various inflammatory mediators, generation of oxygen and nitrogen radicals and oxidants, and immunological alteration. ${ }^{26}{ }^{27}$ Therefore, it is conceivable that the mechanisms responsible for IBD in animals and humans are notably different. Nevertheless, based on the current data, we propose that the oxidative and nitrosative changes and the lethality associated with TNBS induced murine colitis require iNOS activation. Together with previous reports, our study provides further evidence of the critical role of iNOS derived NO in the pathogenesis of colitis in experimental animals. However, whether iNOS activation has a role in the immunoregulatory and inflammatory processes in humans needs further investigation.

1 Salzman AL. Nitric oxide in the gut. New Horizons 1995;3:33-45.

2 Stark ME, Szurszewski JH. Role of nitric oxide in gastrointestinal and hepatic function and disease. Gastroenterology 1992;103:1928-49.

3 Alican I, Kubes P. A critical role for nitric oxide in intestinal barrier function and dysfunction. Am $\mathcal{F}$ Physiol 1996;270: G225-37.

4 Khan BV, Harrison DG, Olbrych MT, et al. Nitric oxide regulates vascular cell adhesion molecule-1 gene expression and redox-sensitive transcriptional events in human vascuar endothelial cells. Proc Natl Acad Sci USA 1996;93: 9114-19.

5 Aiko S, Grisham MB. Spontaneous intestinal inflammation and nitric oxide metabolism in HLA-B27 transgenic rats. Gastroenterology 1995;109:142-50.

6 Yamada T, Sartor RB, Marshall S, et al. Mucosal injury and inflammation in a model of chronic granulomatous colitis in rats. Gastroenterology 1993;106:759-71.

7 Ribbons KA, Zhang X-J, Thompson JH, et al. Potential role of nitric oxide in a model of chronic colitis in rhesus macaques. Gastroenterology 1995;109:1475-83.

8 Miller MJS, Sadowska-Krowicka H, Chotinaruemol S, et al. Amelioration of chronic ileitis by nitric oxide inhibition. $\mathcal{f}$ Pharmacol Exp Ther 1993;264:11-16.

9 Hogaboam CM, Jacobson K, Collins SM, et al. The selective beneficial effects of nitric oxide inhibition in experimental colitis. Am f Physiol 1995;31:G673-84.

10 Mourelle M, Vilaseca J, Guarner F, et al. Toxic dilatation of colon in a rat model of colitis is linked to an inducible form of nitric oxide synthase. Am F Physiol 1996;33:G425-30.

11 Rachmilewitz D, Karmeli F, Okon E. Sulfhydryl blockerinduced rat colonic inflammation is ameliorated by inhibition of nitric oxide synthase. Gastroenterology 1995;109:98106.

12 Kiss J, Lamarque D, Delchier JC, et al. Time-dependent actions of nitric oxide synthase inhibition on colonic inflammation induced by trinitrobenzene sulfonic acid in rats. Eur $\mathcal{F}$ Pharmacol 1997;336:219-24.

13 Zingarelli B, Szabó C, Salzman AL. Mercaptoethylguanidine, a combined inhibitor of nitric oxide synthase and peroxynitrite scavenger, reduces trinitrobenzene sulfonic acidinduced colonic damage in rats. F Pharmacol Exp Ther 1998;287:1048-55.

14 Middleton SJ, Shorthouse M, Hunter JD. Increased nitric oxide synthesis in ulcerative colitis. Lancet 1993;341:465-6.

15 Boughton-Smith NK, Evans SM, Hawkey CJ, et al. Nitric oxide synthase activity in ulcerative colitis and Crohn's disease. Lancet 1993;341:338-40.

16 Lundberg JO, Hellstrom PM, Lundberg JM, et al. Greatly increased luminal nitric oxide in ulcerative colitis. Lancet 1994;344:1673-4.

17 Ikeda I, Kasajima T, Ishiyama S, et al. Distribution of inducible nitric oxide synthase in ulcerative colitis. $A m \mathcal{F}$ Gastroenterol 1997;92:1339-41.

18 Beckman JS, Beckman TW, Chen J, et al. Apparent hydroxyl radical production by peroxynitrite: implication for en-
dothelial injury from nitric oxide and superoxide. Proc Acad Sci USA 1990;87:1260-4.

19 Beckman JS. Oxidative damage and tyrosine nitration from peroxynitrite. Chem Res Toxicol 1996;9:836-44.

20 Miller MJS, Thompson JH, Zhang X-J, et al. Role of inducible nitric oxide synthase expression and peroxynitrite formation in guinea pig ileitis. Gastroenterology 1995;109: mation in 
21 Rachmilewitz D, Stamler JS, Karmeli F, et al. Peroxynitriteinduced rat colitis - a new model of colonic inflammation. 1681-8.

22 McCafferty DM, Mudgett JS, Swain MG, et al. Inducible nitric oxide synthase plays a critical role in resolving intestinal inflammation. Gastroenterology 1997;112:1022-7.

23 Pfeiffer CJ, Qiu BS. Effects of chronic nitric oxide synthase inhibition on TNB-induced colitis in rats. 7 Pharm Pharmacol 1995;47:827-32.

24 Laubach VE, Shesely EG, Smithies O, et al. Mice lacking inducible nitric oxide synthase are not resistant to lipopolysaccharide-induced death. Proc Natl Acad Sci USA 1995;92:10688-92.

25 Neurath MF, Fuss I, Kelsall BL, et al. Antibodies to interleukin 12 abrogate established experimental colitis in mice. $\mathcal{F}$ Exp Med 1995;182:1281-90.

26 Elson CO, Sartor RB, Tennyson GS, et al. Experimental models of inflammatory bowel disease. Gastroenterology 1995;109:1344-67.

27 Morris GP, Beck PL, Herridge MS, et al. Hapten-induced model of chronic inflammation and ulceration in the rat. model of chronic inflammation and

28 Zingarelli $\mathrm{B}$, O'Connor $\mathrm{M}$, Wong $\mathrm{H}$, et al. Peroxynitritemediated DNA strand breakage activates poly-ADP ribosyl synthetase and causes cellular energy depletion in macrophages stimulated with bacterial lipopolysaccharide. $f$ Immunol 1996;156:350-8

29 Zingarelli B, Squadrito F, Graziani P, et al. Effects of zileuton, a new 5-lipoxygenase inhibitor, in experimentally induced colitis in rats. Agents Actions 1993;39:150-6.

30 Krawisz JE, Sharon P, Stenson WF. Quantitative assay for acute intestinal inflammation based on myeloperoxidase activity. Assessment of inflammation in rat and hamster models. Gastroenterology 1984;87:1344-50.

31 Oshitani N, Campbell A, Bloom S, et al. Adhesion molecule expression on vascular endothelium and nitroblue tetrazolium reducing activity in human colonic mucosa. Scand $\mathcal{F}$ Gastroenterol 1995;30:915-20.

32 Ohkawa H, Ohishi N, Yagi K. Assay for lipid peroxides in animal tissues by thiobarbituric acid reaction. Anal Biochem 1979;95:351-8.

33 Shiratora Y, Aoki S, Takada $\mathrm{H}$, et al. Oxygen-derived free radical generating capacity of polymorphonuclear cells in patients with ulcerative colitis. Digestion 1989;44:163-71.

34 Binion DG, West GA, Ina K, et al. Enhanced leukocyte binding by intestinal microvascular endothelial cells in inflammatory bowel disease. Gastroenterology 1997;112 1895-907.

35 Grisham MB. Oxidants and free radicals in inflammatory bowel disease. Lancet 1994;344:859-61.

36 Simmonds NJ, Allen RE, Stevens TRJ, et al. Chemiluminescence assay of mucosal reactive oxygen metabolites in inflammatory bowel disease. Gastroenterology 1992;103: 186-96.

37 McKenzie SJ, Baker MS, Buffinton GD, et al. Evidence of oxidant-induced injury to epithelial cells during inflammatory bowel disease. 7 Clin Invest 1996;98:136-41.

38 Halliwell B. What nitrates tyrosine? Is nitrotyrosine specific as a biomarker of peroxynitrite formation in vivo? FEBS as a biomarker of pero

39 Eiserich JP, Cross CE, Jones AD, et al. Formation of nitrating and chlorinating species by reaction of nitrite with hypochlorous acid. A novel mechanism for nitric oxidemediated protein modification. F Biol Chem 1996;271 19199-208.

40 Eiserich JP, Hristova M, Cross CE, et al. Formation of nitric oxide derivatives catalysed by myeloperoxidase in neutrophils. Nature 1998;391:393-7.

41 Kolios G, Rooney N, Murphy CT, et al. Expression of inducible nitric oxide synthase activity in human colon epithelial cells: modulation by T lymphocyte derived cytokines. Gut 1998;43:56-63.

42 Kimura H, Hokari R, Miura S, et al. Increased expression of an inducible isoform of nitric oxide synthase and the formation of peroxynitrite in colonic mucosa of patients with active ulcerative colitis. Gut 1998;42:180-7.

43 Singer II, Kawka DW, Scott S, et al. Expression of inducible nitric oxide synthase and nitrotyrosine in colonic epithenitric oxide synthase and nitrotyrosine in colonic epithelium in inflam

44 Yasmin W, Strynadka KD, Schulz R. Generation of peroxynitrite contributes to ischemia-reperfusion injury in isolated rat hearts. Cardiovasc Res 1997;33:422-32.
45 Koizumi M, King N, Lobb R, et al. Expression of vascular adhesion molecules in inflammatory bowel disease. Gastroadhesion molecules in inflam

46 Ohtani H, Nakamura S, Watanabe Y, et al. Light and electron microscopic immunolocalization of endothelial leukocyte adhesion molecule- 1 in inflammatory bowel disease. Virchows Arch 1993;420:403-9.

47 Yang H, Vora DK, Targan SR, et al. Intercellular adhesion molecule 1 gene associations with immunologic subsets of inflammatory bowel disease. Gastroenterology 1995;109: $440-8$.

48 Parkos CA, Colgan SP, Diamond MS, et al. Expression and polarization of intercellular adhesion molecule-1 on human intestinal epithelia: consequences for $\mathrm{CD} 11 \mathrm{~b} / \mathrm{CD} 18-$ mediated interactions with neutrophils. Mol Med 1995;2: 489-505.

49 Elsner J, Sach M, Knopf HP, et al. Synthesis and surface expression of ICAM-1 in polymorphonuclear neutrophilic eukocytes in normal subjects and during inflammatory disease. Immunobiology 1995;193:456-64.

50 Hickey MJ, Sharkey KA, Sihota EG, et al. Inducible nitric oxide synthase-deficient mice have enhanced leukocyte-
endothelium interactions in endotoxemia. FASEB $\mathcal{7} 1997$; 11:955-64.

51 Khan IA, Schwartzman JD, Matsuura $\mathrm{T}$, et al. A dichotomous role for nitric oxide during acute Toxoplasma gondii infection in mice. Proc Natl Acad Sci USA 1997;94: 13955-60.

52 MacNaughton WK, Cirino G, Wallace JL. Endotheliumderived relaxing factor (nitric oxide) has protective actions in the stomach. Life Sci 1989;45:1869-76.

53 Buell MG, Berin MC. Neutrophil-independence of the initiation of colonic injury. Comparison of results from three models of experimental colitis in the rat. Dig Dis Sci 1994; 39:2575-88.

54 Sekizuka E, Grisham MB, Li $\mathrm{M}$, et al. Inflammationinduced intestinal hyperemia in the rat: role of neutrophils. Gastroenterology 1988;95:1528-34.

55 Yamada T, Zimmermann BJ, Specian RD, et al. Role of neutrophils in acetic acid-induced colitis in rats. Inflammation 1991;15:399-411.

56 Rubbo H, Radi R, Trujillo M, et al. Nitric oxide regulation of superoxide and peroxynitrite-dependent lipid peroxidation. Formation of novel nitrogen-containing oxidized lipid derivatives. F Biol Chem 1994;269:26066-75.

57 Gadelha FR, Thomson L, Fagian MM, et al. Ca2+independent permeabilization of the inner mitochondrial membrane by peroxynitrite is mediated by membrane protein thiol cross-linking and lipid peroxidation. Arch Biochem Biophys 1997;345:243-50.

58 Lamarque D, Whittle BJ. Involvement of peroxynitrite in the lipid peroxidation induced by nitric oxide in rat gastric mucosa. Eur f Pharmacol 1996;313:R5-7.

59 Traylor LA, Mayeux PR. Nitric oxide generation mediates lipid A-induced oxidant injury in renal proximal tubes. Arch Biochem Biophys 1997;338:129-35.

60 Kennedy MS, Denenberg A, Szabó C, et al. Poly (ADP-ribose) synthetase (PARS) mediates increased permeability induced by peroxynitrite in $\mathrm{CaCo}-2 \mathrm{BBe}$ cells. Gastroenterology 1998;114:510-18.

61 Drapier JC. Interplay between NO and [Fe-S] clusters: relevance to biological systems. Methods 1997;11:319-29.

62 Reif DW. Ferritin as a source of iron for oxidative damage. Free Radic Biol Med 1992;12:417-27.

63 MacMicking JD, Nathan C, Hom G, et al. Altered responses to bacterial infection and endotoxic shock in mice lacking inducible nitric oxide synthase. Cell 1995;81:641-50.

64 Wei X-Q, Charles IG, Smith A, et al. Altered immune responses in mice lacking inducible nitric oxide synthase. Nature 1995;375:408-11.

65 Gilkeson GS, Mudgett JS, Seldin MF, et al. Clinical and serologic manifestations of autoimmune disease in MRL$\mathrm{pr} / \mathrm{lpr}$ mice lacking nitric oxide synthase type 2. F Exp Med 1997;186:365-73.

66 Fenyk-Melody JD, Garrison A, Brunnert S, et al. Experimental autoimmune encephalomyelitis is exacerbated in mice lacking the NOS2 gene. F Immunol 1998;160:2940-6.

67 MacMicking J, North RJ, LaCourse R, et al. Identification of nitric oxide synthase as a protective locus against tuberculosis. Proc Natl Acad Sci USA 1997;94:5243-8. 